\title{
Reactive processing of maleic anhydride-grafted $A B S$ and its compatibilizing effect on PC/ABS blends
}

\author{
Erick Gabriel Ribeiro dos Anjos ${ }^{1}$ (D), Juliano Marini (D), Larissa Stieven Montagna ${ }^{1}$ (D), \\ Thaís Larissa do Amaral Montanheiro ${ }^{3}$ (D) and Fabio Roberto Passador ${ }^{1 *}$ (D)
}

\author{
'Laboratório de Tecnologia em Polímeros e Biopolímeros - TecPBio, Departamento de Ciência e \\ Tecnologia - DCT, Instituto de Ciência e Tecnologia - ICT, Universidade Federal de São Paulo - UNIFESP, \\ São José dos Campos, SP, Brasil \\ ${ }^{2}$ Departamento de Engenharia de Materiais - DEMa, Universidade Federal de São Carlos - UFSCar, São \\ Carlos, SP, Brasil \\ ${ }^{3}$ Laboratório de Plasmas e Processos - LPP, Instituto Tecnológico de Aeronáutica - ITA, São José dos \\ Campos, SP, Brasil \\ *fabio.passador@unifesp.br
}

\begin{abstract}
Polymer compatibilizer agents are crucial for industrial materials development. Compatibilizer agents may be prepared by melt-grafting in the reactive extrusion process which is cheaper and environmentally friendly. Maleic anhydride-grafted acrylonitrile-butadiene-styrene (ABS- $g$-MA) has emerged as a relevant compatibilizer agent for immiscible blends, like polycarbonate (PC)/ABS. In this work, ABS- $g$-MA was prepared by a simple reactive extrusion process using ABS, maleic anhydride (MA) and benzoyl peroxide (BPO). The MA:BPO ratios of 1:0.5 and 1:1 varying the content of MA by 1,2 and $5 \mathrm{wt} \%$ were investigated. The grafting reaction was confirmed through Fourier transform infrared spectroscopy (FT-IR), grafted degree (GD\%), thermal and rheological analysis. The effectiveness of the compatibilizer agent was evaluated in PC/ABS blends (70/30 and 85/15 blend ratios). The addition of $5 \mathrm{wt} \%$ of ABS-g-MA (5 MA:2.5 BPO) in the $\mathrm{PC} / \mathrm{ABS}$ blends promoted an expressive reduction of ABS domain sizes and better dispersion in the $\mathrm{PC}$ matrix.
\end{abstract}

Keywords: ABS-g-MA, melt-grafting, blends, compatibilizer agent, reactive extrusion.

How to cite: Anjos, E. G. R., Marini, J., Montagna, L. S., Montanheiro, T. L. A., \& Passador, F. R. (2020). Reactive processing of maleic anhydride-grafted ABS and its compatibilizing effect on PC/ABS blends. Polimeros: Ciência e Tecnologia, 30(4), e2020039. https://doi.org/10.1590/0104-1428.09220.

\section{Introduction}

Polymeric compatibilizer agents are used to obtaining new materials by combining the best features of already commercial materials, as polymer blends and polymer composites ${ }^{[1]}$. In the specific case of polymer blends, most systems are composed by polymers of different chemical nature, which can cause a weak interface between two different phases and compromises its mechanical properties ${ }^{[2-5]}$. An efficient way to overcome this problem is the use of a compatibilizer agent to improve the dispersion and the distribution of the second phase in the matrix, thereby promoting a better interaction between these components ${ }^{[4-6]}$.

Several types of compatibilizer agents can be used in polymer blends, especially polymers grafted with reactive groups, block copolymers and polymers with polar groups ${ }^{[7,8]}$. The first group is popular and used for reactive blending, and can be used in polycarbonate (PC)/ acrylonitrile-butadiene-styrene $(\mathrm{ABS})$ blends ${ }^{[8-10]}$, polyamide 6 (PA6)/ABS ${ }^{[11,12]}$ and polyethylene (PE)/PA6 blends ${ }^{[13]}$. In these cases, the backbone of the compatibilizer agent usually is chemically compatible with the non-polar phase and the grafting group reacts with the other phase, providing the copolymer formation at the interface ${ }^{[8]}$. This process promotes a stronger interface and decreases the interfacial energy ${ }^{[8]}$ and as a consequence, there are improvements in the mechanical properties of the blends.

In this way, the grafting of maleic anhydride (MA) on the backbone of a rubber or a non-polar polymer is an important type of compatibilizer agent ${ }^{[6,14]}$. There are some commercial grades of MA-grafted polymer like polyethylene (PE- $g$-MA $)^{[13]}$, polypropylene (PP- $g$-MA) ${ }^{[15]}$ and polystyrene (PS-g-MA $)^{[14]}$. Among other monomers, used in grafting, MA is preferred due to its high reactivity ${ }^{[16]}$, thermal stability ${ }^{[17,18]}$ and difficulty in homopolymerization ${ }^{[19]}$. For polymer blends, MA is advantageous because may result in less mechanical properties loss when compared with other types of compatibilizer agent like for example the glycidyl acrylate $(\mathrm{GA})^{[10]}$ and is more efficient than methyl methacrylate (MMA) requiring smaller quantities in polymer blends compositions ${ }^{[9]}$.

Several studies have been published ${ }^{[6]}$ about different ways to prepare these graft polymers using vinyl monomers, like MA, GA, and MMA. However, 
the most common method is by chemical initiation ${ }^{[20]}$, also called free-radical grafting ${ }^{[14]}$. Under the industrial technologies available for free-radical grafting there are the solution, emulsion or suspension grafting methods, which can achieve high grafting degree (GD\%) levels, but require high costs and some organic solvent, being environmentally dangerous ${ }^{[6,14]}$. The solid-state graft technology which is solvent-free and achieves high $\mathrm{GD} \%$, nevertheless, requires long reaction times and it is limited to semi-crystalline polymers with high molecular weight. Finally, the most applied technique is the melt-grafting technology that has the advantages of being simple, fast, solvent-free and not limited by polymers melting temperature ${ }^{[14]}$.

MA melt-grafting by reactive extrusion is a wellknown and applied technology in the industry to produce compatibilizer agents ${ }^{[14]}$, which is still being developed because it is strongly dependent on process parameters, like the temperature of the process and the screw configuration of the extruder, and the grafting levels could be improved by using comonomers and mixed initiators ${ }^{[21]}$.

PC/ABS blends are an economical way to improve the balance of mechanical properties of $\mathrm{PC}^{[22,23]}$ and overcome other limitations like being difficult to process due to high melt viscosity and sensitivity to UV degradation ${ }^{[2,24]}$. This balance of properties has made the PC/ABS blend largely used in technical applications as automotive parts ${ }^{[2]}$, and electronic engineering products ${ }^{[23]}$.

MA grafted-ABS (ABS- $g$-MA) has been used successfully for PC/ABS blends. Rao et al. ${ }^{[25]}$ prepared ABS- $g$-MA by solution process using toluene as solvent, evaluating the effect of monomer and initiator concentrations and time reaction. The grafting reaction occured onto butadiene regions of the ABS backbone. Balakrishnan et al. ${ }^{[26]}$ prepared ABS-g-MA by reactive extrusion on a single screw extruder using benzoyl peroxide (BPO) as an initiator and then mixed with PC to verify the efficiency on PC/ABS blends. As a result, an improvement in impact strength and the compatibility of PC/ABS blends were observed with the addition of $2 \mathrm{wt} \%$ of MA in this process.

Aiming to improve the \%GD thought the reactive extrusion process Qi et al. ${ }^{[21]}$ prepared ABS- $g$-MA using two initiators (BPO and dicumyl peroxide - DCP) and styrene as a comonomer. The use of DCP as initiator and the use of a comonomer improved the \%GD due to the longer half-life of DCP compared to BPO at the temperature utilized, and the presence of styrene with MA could form a charge-transfer complex which is more reactive than the individual monomers ${ }^{[21]}$.

In this study, ABS-g-MA was produced through reactive melt-grafting method using $\mathrm{BPO}$ as the initiator and MA at 1:0.5 and 1:1 MA:BPO ratios and varying the content of MA by 1,2 and $5 \mathrm{wt} \%$. The effectiveness of the compatibility was verified in different PC/ABS blends (70/30 and 85/15). In addition, the mechanical and morphological properties of the PC/ABS/ABS-g-MA blends were studied.

\section{Materials and Methods}

\subsection{Materials}

Acrylonitrile-butadiene-styrene copolymer (ABS) was supplied by TRINSEO (specification Magnum 3404, Switzerland), with a PB content of $20 \%$, MFI of $2.0 \mathrm{~g} / 10 \mathrm{~min}$ $\left(230{ }^{\circ} \mathrm{C} / 3.8 \mathrm{~kg}\right)$ and density of $1.05 \mathrm{~g} / \mathrm{cm}^{3}$.

Polycarbonate (PC) was supplied by UNIGEL (Durolon IR-2200, Brazil) with a density of $1.20 \mathrm{~g} / \mathrm{cm}^{3}$ and a melt flow index (MFI) of $12.0 \mathrm{~g} / 10 \mathrm{~min}\left(300^{\circ} \mathrm{C} / 1.2 \mathrm{~kg}\right)$.

Maleic anhydride (MA) was utilized as a monomer and supplied by Sigma-Aldrich (Saint Louis, MO. USA) with $99 \%$ purity. As initiator was used benzoyl peroxide (BPO) commercial grade supplied by Dinâmica Química Contemporânea (Indaiatuba, Brazil). Both reagents were used as received.

\subsection{Reactive processing of $A B S-g-M A$}

Before the reactive processing, ABS was dried at $80^{\circ} \mathrm{C}$ for at least $12 \mathrm{~h}$ in a vacuum oven to minimize the hydrolytic degradation during the processing. The reactive extrusion processes to produce ABS-g-MA by melt-grafting were carried out in a co-rotational twin-screw extruder, AX Plásticos, model AX16:40DR (L/D = 40, D = $16 \mathrm{~mm})$, with screw rotation speed set in $80 \mathrm{rpm}$ and feeding in $20 \mathrm{rpm}$. The temperature profile set was $190 / 200 / 200 / 200 / 210{ }^{\circ} \mathrm{C}$ from the first zone to the die, in these conditions the residence time was near to $2 \mathrm{~min}$. After extrusion, the materials were pelletized and dried on a vacuum oven for $4 \mathrm{~h}$ at $80^{\circ} \mathrm{C}$. Table 1 presents the compositions studied with the variation contents of MA and BPO.

\subsection{Characterization of the compatibilizer agent - ABS-g-MA}

\subsubsection{FT-IR Spectroscopy}

ABS-g-MA with different MA:BPO ratios were analyzed by Fourier transform infrared spectroscopy (FTIR) using universal attenuated total reflectance (UATR) in a PerkinElmer Frontier equipment and a scan range of $400-4000 \mathrm{~cm}^{-1}$.

\subsubsection{Grafting degree (\%GD)}

The grafting degree of MA in the melt-grafted compatibilizer agents was determined by a back-titration procedure based on the methodology described by Qi et al. ${ }^{[22]}$. First, after the reactive extrusion process, the compatibilizer agents were purified by dissolving in $5 \mathrm{~mL}$ of acetone and precipitated adding $5 \mathrm{~mL}$ of ethanol, twice, to remove the residual reactants (MA and BPO). Then, $0.5 \mathrm{~g}$ of each composition

Table 1. Nomenclature and compositions studied.

\begin{tabular}{cccc}
\hline Composition & ABS (wt\%) & MA (wt\%) & BPO (wt\%) \\
\hline C1 & 98.5 & 1 & 0.5 \\
C2 & 98 & 1 & 1 \\
C3 & 97 & 2 & 1 \\
C4 & 96 & 2 & 2 \\
C5 & 92.5 & 5 & 2.5 \\
C6 & 90 & 5 & 5 \\
\hline
\end{tabular}


was dissolved in $50 \mathrm{~mL}$ of acetone and $5 \mathrm{~mL}$ of ethanol. $\mathrm{NaOH}(1.0 \mathrm{~mol} / \mathrm{L})$ solution was added with $0.5 \mathrm{~mL}$ of Yamada Universal indicator. After $30 \mathrm{~min}$ with mechanical stirring, these solutions were back titrated with $0.1 \mathrm{~mol} / \mathrm{L}$ of HCL. Then, the quantity of MA grafted was calculated as a percentage of $\mathrm{ABS}$ by the following:

$$
\% \mathrm{GD}=\frac{\left(\mathrm{V}_{\mathrm{RABS}}-\mathrm{V}_{\mathrm{S}}\right) \times 10^{-3} \times \mathrm{C}_{\mathrm{HCl}} \times \mathrm{MW}_{\mathrm{MA}}}{2 \mathrm{~W}_{\mathrm{S}}} \times 100
$$

Where VRABS is the volume $(\mathrm{mL})$ of $\mathrm{HCl}$ solution consumed with neat $\mathrm{ABS}$ as a reference, VS is the volume consumed by the sample $(\mathrm{mL}), \mathrm{CHCl}$ is constant and corresponds to $0.1 \mathrm{~mol} / \mathrm{L}$ of $\mathrm{HCl}$ titration solution, MWMA is the molecular weight of MA, also a constant used as $98.06 \mathrm{~g} / \mathrm{mol}$ and Ws is the weight of each sample (g).

\subsubsection{Rheological characterization}

The rheological behavior of the compositions were evaluated in a rotational controlled stress rheometer from TA Instruments, model ARG2. The steady-state viscosity was evaluated as a function of the shear rate in an inert nitrogen atmosphere at a temperature of $210{ }^{\circ} \mathrm{C}$, using parallel-plates geometry with $25 \mathrm{~mm}$ of diameter and gap of $1 \mathrm{~mm}$. The delay before measurement was determined from stress overshoot experiments performed at $210^{\circ} \mathrm{C}$ and $0.01 \mathrm{~s}^{-1}$ until constant stress was attained.

\subsection{Melt flow index (MFI)}

MFI values of the compositions were analyzed according to the ASTM D1238 standard ${ }^{[27]}$, a Hebert Lambert plastometer was utilized at $200{ }^{\circ} \mathrm{C}$ and a load of $5 \mathrm{~kg}$.

\subsubsection{Differential Scanning Calorimetry (DSC)}

The glass transition $\left(\mathrm{T}_{\mathrm{g}}\right)$ of SAN phase of ABS for the compositions were analyzed by DSC. The tests were performed in a TA Instruments equipment, model Q2000 under nitrogen atmosphere. Samples were sealed in an aluminum DSC pan and heated from room temperature to $220^{\circ} \mathrm{C}$ at $10^{\circ} \mathrm{C} / \mathrm{min}$, followed by an isothermal at $220^{\circ} \mathrm{C}$ for $3 \mathrm{~min}$, a cooling cycle to $30^{\circ} \mathrm{C}$ at $10^{\circ} \mathrm{C} / \mathrm{min}$ and a second heating cycle up to $220^{\circ} \mathrm{C}$ also at $10^{\circ} \mathrm{C} / \mathrm{min}$.

\subsubsection{Thermogravimetric Analysis (TGA)}

Thermogravimetric analysis (TGA) of the compositions were performed on a Netzsch model Iris ${ }^{\circledR}$ TG 209 F1 equipment from room temperature to $800{ }^{\circ} \mathrm{C}$ at a heating rate of $20^{\circ} \mathrm{C} / \mathrm{min}$, under nitrogen atmosphere.

\subsection{Effectiveness of the compatibilizer agent in $P C / A B S$ blends}

The effectiveness of the ABS- $g$-MA as a compatibilizer agent was verified for $\mathrm{PC} / \mathrm{ABS}$ blends. $\mathrm{PC} / \mathrm{ABS}$ blends with different blend ratios (70/30 and 85/15) were prepared using $5 \mathrm{wt} \%$ of each ABS- $g$-MA produced replacing neat ABS. All blends were produced using an AX Plásticos, model AX16:40DR co-rotational twin-screw extruder with screw rotation speed set in $80 \mathrm{rpm}$ and feeding in $20 \mathrm{rpm}$ with the temperature profile of $225 / 235 / 245 / 245 / 255{ }^{\circ} \mathrm{C}$ from the first section to the die. The blends were pelletized and dried on a vacuum oven for $4 \mathrm{~h}$ at $80^{\circ} \mathrm{C}$.
Specimens for Izod impact strength tests were pressed into $3.2 \mathrm{~mm}$ thick plates in a hydropneumatic press (MH Equipamentos Ltda, model PR8HP) at $260^{\circ} \mathrm{C}$ with a pressure of 5 bar for $7 \mathrm{~min}$.

\subsection{Characterization of the $P C / A B S$ blends}

\subsubsection{Impact lzod test}

Izod impact strength tests were performed on a CEAST/Instron Izod impactor test machine (model 9050) according ASTM D256-06 ${ }^{[28]}$. All the test specimens were notched using a manual notched machine (CEAST/Instron) and the tests were performed using a $5.5 \mathrm{~J}$ hammer, the largest hammer available for testing, five samples of each composition were tested.

MINITAB $^{\circledR} 17$ statistical software was used to the Izod impact strength data. First, the data distribution was analyzed by Anderson-Darling test for each composition, then the Levane test was used to evaluate the homogeneity between variances of different compositions ${ }^{[29]}$. Analyses of variance one-way (ANOVA) were performed to compare the mean size distributions and mean impact strength among the groups, followed by post-HOC Tukey HSD test to compare each pair at $\alpha=0.05^{[29,30]}$.

\section{Morphological characterization with scanning electron microscopy (SEM)}

The morphology of the PC/ABS blends were analyzed using a FEI Inspect S50 scanning electron microscope operating at $15 \mathrm{keV}$. The samples of each blend composition were taken immediately at the exit of the extruder die to verify the formation of phases during the extrusion process. These samples were cryogenically fractured with liquid nitrogen, to preserve the morphology, perpendicularly to flow direction and the surfaces were coated with a thin gold layer. To obtain the average and distribution of ABS domains sizes the SEM images were analyzed with the software Image J. First, one image of each blend composition was selected on the same amplified magnitude (10000x), $50 \mathrm{ABS}$ domains ${ }^{[11]}$ were selected and measured a minimum of ten times each. Then these data were compiled to create a normal size distribution.

\section{Results and Discussions}

\subsection{Characterization of $A B S-g-M A$}

Figure 1A shows the FTIR spectra of ABS and the compatibilizer agents $(\mathrm{C} 1-\mathrm{C} 6)$. For all compositions, it is possible to observe the main $\mathrm{ABS}$ characteristics bands. The band at $2238 \mathrm{~cm}^{-1}$ corresponding the $\mathrm{C} \equiv \mathrm{N}$ stretch of acrylonitrile ${ }^{[20,31]}$, the bands at $1494 \mathrm{~cm}^{-1}$ and $1602 \mathrm{~cm}^{-1}$ are associated to styrene ring modes and bands at 911 and $966 \mathrm{~cm}^{-1}$ are associated to $\mathrm{C}-\mathrm{H}$ in plane bending in polybutadiene $(\mathrm{PB})^{[31,32]}$. The bands at 759 and $700 \mathrm{~cm}^{-1}$ are correlated to bends of C-H styrene rings and $1453 \mathrm{~cm}^{-1}$ indicating the scissoring mode of $\mathrm{CH}_{2}$ bonds. And some general peaks like $3200-3000 \mathrm{~cm}^{-1}$ which are associated to aromatic the C-H stretches and $3000-2800 \mathrm{~cm}^{-1}$ to the aliphatic one ${ }^{[31]}$. For the ABS- $g$-MA curves $(\mathrm{C} 1$ to $\mathrm{C} 6)$ it is possible to observe a new absorbance band at $1780 \mathrm{~cm}^{-1}$ 

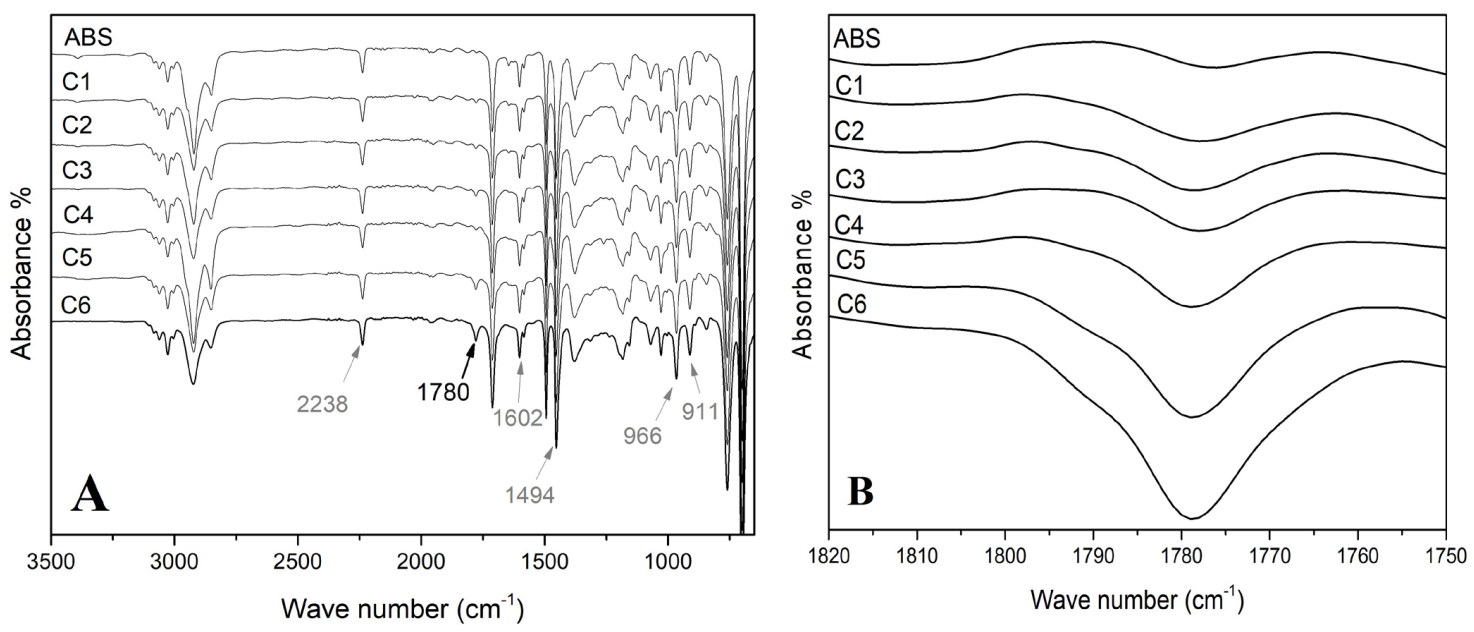

Figure 1. FTIR spectra (A) spectra of ABS and ABS-g-MA (C1 to C6) and (B) detail of $1780 \mathrm{~cm}-1$ peak for all composition.

which corresponds to the $\mathrm{C}=\mathrm{O}$ stretching from anhydride indicating that MA was grafted in the ABS backbone ${ }^{[20,32]}$. This peak also increases with the concentration of MA and $\mathrm{BPO}^{[32]}$, as is sown in Figure 1B. As shown by Braga et al..$^{[33]}$ the $\mathrm{C}=\mathrm{O}$ stretching band from MA is located at $1709 \mathrm{~cm}^{-1}$. The new absorption band observed in the compatibilizer agents is located at $1780 \mathrm{~cm}^{-1}$ and refers to $\mathrm{C}=\mathrm{O}$ stretching from anhydride. This shift in the wavelength means that MA was covalently bonded to the ABS backbone, and that the grafting reaction was effective $\mathrm{e}^{[34,35]}$ suggested by some authors the MA was preferentially grafted onto PB segments of ABS backbone ${ }^{[32]}$.

The efficiency of the reactive extrusion process could be associated with grafting degree of MA (\%GD) determined by back-titration method and exhibited in Figure 2. For an ease understand of the results, the compositions could be divided into two groups: First, C1, C3 and, C5 which were prepared with 1:0.5 MA:BPO ratio and second, $\mathrm{C} 2, \mathrm{C} 4$, and $\mathrm{C} 6$ with 1:1 MA:BPO ratio. First, the \%GD increased with the MA concentration comparing composition into each group. This might be associated with the increase in the number of molecules diffusing in the reaction medium (the molten polymer), therefore increasing the probability of grafting reaction onto the polymer back-bone ${ }^{[32]}$. Then, an analogous behavior was observed for the initiator concentration when comparing compositions with 1:0.5 MA:BPO and 1:1 MA:BPO. It may be explained by an increase of free radicals formed from thermal decomposing of $\mathrm{BPO}^{[32]}$. However, even working with high contents of MA and BPO ( $5 \mathrm{wt} \%$ of each component) the grafting degree is still less than $2.0 \mathrm{wt} \%$, as supported the literature on similar process conditions $^{[14]}$. Another side effect of high initiator and monomer content is polymer chains scissions ${ }^{[21]}$. In order to understand this effect, the MFI was measured, and the rheological behavior was analyzed.

MFI for ABS-g-MA of all compositions is also shown in Figure 2. It was found that the MFI of ABS- $g$-MA was higher than the neat ABS resin (around $2.0 \mathrm{~g} / 10 \mathrm{~min}$ ). The MFI of the compatibilizer agents increased with BPO and MA content. The presence of higher levels of BPO has a

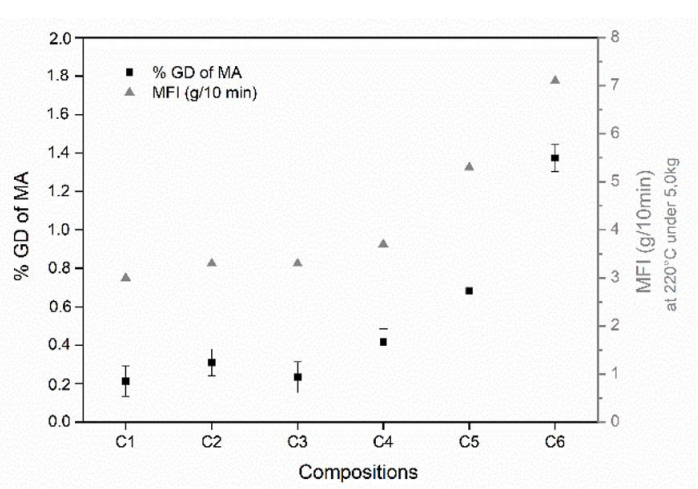

Figure 2. Grafting degree of MA (\%GD) and MFI of ABS- $g$-MA compositions.

greater influence on MFI values and the MFI behavior could explain some thermal degradation of ABS under processing conditions. Moreover, a lubricant effect caused by a residual amount of MA and BPO can increase MFI value. A decrease in MFI can occur if the grafting reaction was predominant than chain scission ${ }^{[32]}$.

The rheological behavior under low shear rates $\left(0.01-1.0 \mathrm{~s}^{-1}\right)$ conditions is commonly used as an indirect way to understand some structural modifications on polymers. At this range of shear rates, a Newtonian behavior is expected for the majority of the thermoplastics and in this analysis the viscosity values for the first Newtonian plateau $\left(\eta_{0}\right)$ will be considered as those measured at $0.01 \mathrm{~s}^{-1}[33]$. Figure 3 shows the viscosity as function of the shear rate of the samples at $210^{\circ} \mathrm{C}$.

Comparing the rheological behavior of ABS pellet and the processed $\mathrm{ABS}$ it is possible to conclude that the processing conditions applied had no significant influence on the material molecular structure. For the ABS-g-MA compositions ( $\mathrm{C} 1$ to $\mathrm{C} 6)$ the $\eta_{0}$ were lower than ABS. The extension of the Newtonian plateau for all samples is small, restricted to very low shear rates and the greater the MA and BPO contents (samples C5 and C6) the smaller the 
plateau extension. Thus ABS and ABS-g-MA presented a pseudo-plastic behavior even at low shear rates. Agreeing to MFI results, the viscosity reduction may be associated with molecular weight reduction, due to ABS chain scissions ${ }^{[34]}$ and a possible lubricant effect of a residual amount of BPO and MA molecules.

Table 2 presents the values of glass transition temperature $\left(\mathrm{T}_{\mathrm{g}}\right)$ of SAN present in ABS for first and second heating. First, comparing $T_{g}$ values between the heating cycles is clearly observed that the $T_{g}$ is higher in the second heat cycle for all compositions. It might indicate the presence of some molecule acting as a plasticizer which exudates on the first heating cycle ${ }^{[24]}$, and on the present context, could be non-reacted BPO and MA molecules or some molecules with little molecular weight formed between them.

Comparing the $\mathrm{T}_{\mathrm{g}}$ values it was observed a decrease in $\mathrm{T}_{\mathrm{g}}$ with the MA content. One hypothesis is that MA grafting reactions and the degradation of ABS occur simultaneously during reactive extrusion and both events affect the $T_{g}$ value. MA grafted on ABS chains could increase $T_{g}$ making it more rigid $^{[24,32]}$. However, the short MA branches ${ }^{[8]}$ and more chain ends ${ }^{[24]}$ resultant from the chains scissions decrease the $\mathrm{T}_{\mathrm{g}}$ value. Even some authors had observed the opposite behavior for the $\mathrm{T}_{\mathrm{g}}{ }^{[32]}$, but for ABS- $g$-MA prepared on the solvent approach which is less susceptible to degradation

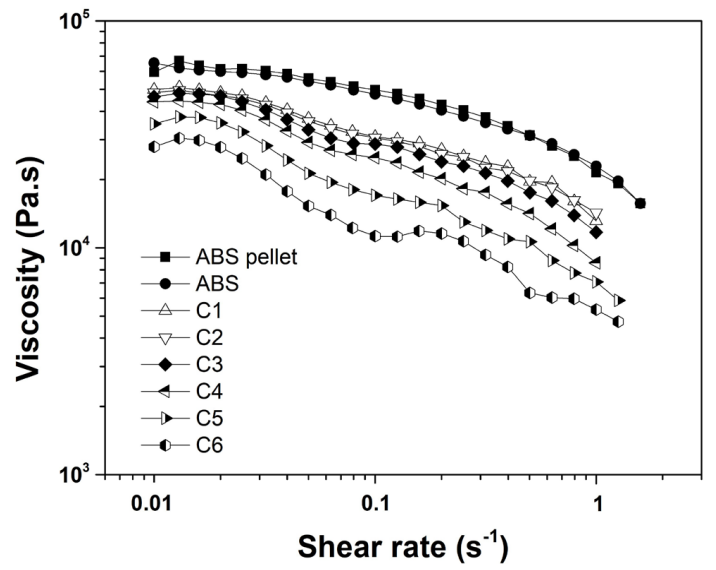

Figure 3. Viscosity curve as a function of the shear rate obtained by deformational rheometry of non-processed ABS (ABS pellet), processed $\mathrm{ABS}(\mathrm{ABS})$ and $\mathrm{ABS}-\mathrm{g}-\mathrm{MA}(\mathrm{C} 1-\mathrm{C} 6)$ compositions. of $\mathrm{ABS}^{[14]}$, so that supports a possible degradation process on higher contents of BPO and MA.

The TGA results are expressed in terms of the temperature of 10,50 and $90 \%$ mass loss and temperature of maximum degradation rate $\left(\mathrm{T}_{\max }\right)$, presented in Table 2 .

For ABS- $g$-MA (C4 to C6), it is possible to observe a mass loss before the main degradation step, which is probably associated with residual molecules of MA and BPO. This mass loss increases gradually with the reactant's content. $\mathrm{T}_{10}$ for ABS- $g$-MA was lower than for ABS and decreases gradually for $\mathrm{C} 4$ to $\mathrm{C} 6$, this may be explained by the presence of residual molecules and a possible reduction in molecular weight by oxidative chain scissions on reactive extrusion, supporting the MFI and DSC results.

\subsection{Effectiveness of ABS-g-MA as compatibilizer agent for PC/ABS blends.}

The Izod impact strength values of PC/ABS blends with different blend ratios are shown in Table 3. During the impact test two different specimen failures were observed according to ASTM D256-06 standard. For the most composition occurred a partial break $(\mathrm{P})$, which the specimen had an incomplete break higher than $90 \%$ of the sample length and still supporting itself vertically. On the other hand, for other compositions, the specimens had failed by a complete break (C) been separated into two parts ${ }^{[36]}$.

The ANOVA results for impact strength proved a statistical difference between groups ( $\mathrm{p}$-value of 0.000 and F-Value of 228.64) ${ }^{[29,30,34,35]}$, so the different compositions were classified in statistically different groups by the postHOC Tukey test exhibited in Table 3.

The addition of ABS increases the PC toughness for both $\mathrm{PC} / \mathrm{ABS}$ blend ratios (70/30 and $85 / 15)$ with a synergistic effect, higher to PC/ABS (85/15), agreeing with Greco et al. ${ }^{[37]}$ results for $\mathrm{PC} / \mathrm{ABS}$ blends with ratios between $15-30 \mathrm{wt} \%$ of ABS. The higher impact strength for $85 / 15$ than $70 / 30$ ratio was explained for Lee et al. ${ }^{[36]}$ as a change in the main toughening mechanism. The addition of compatibilizer agents $\mathrm{C} 2$ and $\mathrm{C} 5$ did not significantly change the impact strength in comparison with the non-compatibilized blends for both blend ratios. The compatibilizers $\mathrm{C} 1, \mathrm{C} 3$, and $\mathrm{C} 4$ significantly decreased the impact strength of PC/ABS $(85 / 15)$, which may be associated with a non-homogeneous morphology ${ }^{[10]}$.

Table 2. Values of glass transition (Tg) of SAN phase of ABS on fisrt and second heating. TGA analys results in terms of the temperature of 10,50 and $90 \%$ mass loss and temperature of maximum degradation rate.

\begin{tabular}{|c|c|c|c|c|c|c|}
\hline \multirow{3}{*}{ Sample } & \multicolumn{2}{|c|}{ DSC } & \multicolumn{3}{|c|}{ TGA } & \multirow{2}{*}{$\begin{array}{c}\text { DTG } \\
T_{\max } \\
\end{array}$} \\
\hline & $1^{\text {st }}$ & $2^{\text {nd }}$ & $\mathrm{T}_{10 \%}$ & $\mathrm{~T}_{50 \%}$ & $T_{90 \%}$ & \\
\hline & $\mathrm{Tg}^{*}\left({ }^{\circ} \mathrm{C}\right)$ & $\mathrm{Tg}^{*}\left({ }^{\circ} \mathrm{C}\right)$ & $\left({ }^{\circ} \mathrm{C}\right)$ & $\left({ }^{\circ} \mathrm{C}\right)$ & $\left({ }^{\circ} \mathrm{C}\right)$ & $\left({ }^{\circ} \mathrm{C}\right)$ \\
\hline ABS pellets & 108 & 111 & 395 & 423 & 458 & 421 \\
\hline ABS & 115 & 114 & 389 & 417 & 448 & 415 \\
\hline $\mathrm{C} 1$ & 107 & 109 & 393 & 416 & 447 & 414 \\
\hline $\mathrm{C} 2$ & 102 & 109 & 388 & 416 & 446 & 415 \\
\hline $\mathrm{C} 3$ & 105 & 108 & 391 & 417 & 448 & 416 \\
\hline $\mathrm{C} 4$ & 99 & 106 & 383 & 414 & 445 & 413 \\
\hline $\mathrm{C} 5$ & 84 & 101 & 380 & 414 & 447 & 413 \\
\hline C6 & 86 & 102 & 360 & 409 & 455 & 409 \\
\hline
\end{tabular}


The addition of $\mathrm{C} 6$ as a compatibilizer agent for $\mathrm{PC} / \mathrm{ABS}$ (70/30) and PC/ABS (85/15) resulted in the lowest impact strength, comparable with the values of the neat materials $\mathrm{PC}$ and ABS. C6 is the ABS- $g$-MA with higher content of MA grafted and the degradation by severing chain scissions suffered during the melt-graft process probably generates a weaker interface on PC/ABS blends.

The micrographs of the blends are shown in Figure 4. For all blends, it is possible to observe ABS domains on a $\mathrm{PC}$ matrix which are marked by interface lines.

Comparing PC/ABS (70/30) non-compatibilized blend (Figure 4A) with the compatibilized blend using $\mathrm{C} 3$ (Figure 4B) and C5 (Figure 4C) as compatibilizer agents it is possible to note a gradual reduction on the size of ABS domains. Moreover, a more homogeneous and thinner dispersion for $\mathrm{C} 5$ is observed and is in accordance with other works ${ }^{[9]}$. However, for the PC/ABS blend using C6 as compatibilizer agent (Figure 4D) it is possible to observe that the ABS domains increase, suggesting a coalescence of ABS domains with a heterogeneous form.

Blends morphologies are strongly correlated to the content of each polymer ${ }^{[5]}$. Comparing the two blend ratios (70/30 and 85/15), the PC/ABS (85/15) presents a thinner dispersion and size of the ABS domains. Increasing the content of the higher viscosity phase (PC) causes a change in the viscosity ratio between the disperse phase and the matrix ${ }^{[5]}$. For PC/ABS blend (85/15) the addition of $\mathrm{C} 3$ as a compatibilizer agent results in an increase in the size of $\mathrm{ABS}$ domains, which may be correlated with the lower impact strength for blends PC/ABS (85/15) with the addition of

Table 3. Impact strength test for PC/ABS blends and neat materials (PC and ABS).

\begin{tabular}{ccccc}
\hline & $\begin{array}{c}\text { Impact strength (J/m) } \\
\text { Mean (SD) }\end{array}$ & Fracture type & $\begin{array}{c}\text { p- value } \\
\text { Anderson-Darling test }\end{array}$ & Groups* \\
\hline PC & $73.8(3.1)$ & Complete break & 0.494 & $\mathrm{~F}$ \\
ABS & $124.8(0.9)$ & Complete break & 0.102 & EF \\
B70 & $428.8(28.1)$ & Partial Break & 0.505 & B \\
B70C1 & $436.6(23.4)$ & Partial Break & 0.139 & B \\
B70C2 & $427.4(14.8)$ & Partial Break & 0.873 & B \\
B70C3 & $358.2(11.1)$ & Partial Break & 0.109 & CD \\
B70C4 & $319.4(27.3)$ & Partial Break & 0.187 & BC \\
B70C5 & $403.8(14.4)$ & Partial Break & 0.364 & B \\
B70C6 & $150.5(5.3)$ & Complete break & 0.350 & F \\
B85 & $533.0(25.7)$ & Partial Break & 0.178 & B \\
B85C1 & $445.0(20.8)$ & Partial Break & 0.056 & A \\
B85C2 & $514.4(28.9)$ & Partial Break & 0.248 & E \\
B85C3 & $138.0(50.1)$ & Complete break & 0.238 & D \\
B85C4 & $90.4(6.3)$ & Complete break & 0.520 & A \\
B85C5 & $522.3(19.0)$ & Partial Break & 0.160 & F \\
B85C6 & $70.1(31.0)$ & Complete break & 0.064 & \\
\hline
\end{tabular}

*By post-HOC Tukey's test, mean values which do not share letters are significantly different from others. **P-value Levene test 0.336 . $* * *$ ANOVA results $\mathrm{p}$-Value $=0.000, \mathrm{~F}-$ Value $=228.64, \mathrm{~S}=22.9979 \mathrm{~J} / \mathrm{m}$, and $\mathrm{R}^{2}=98.62 \%$.
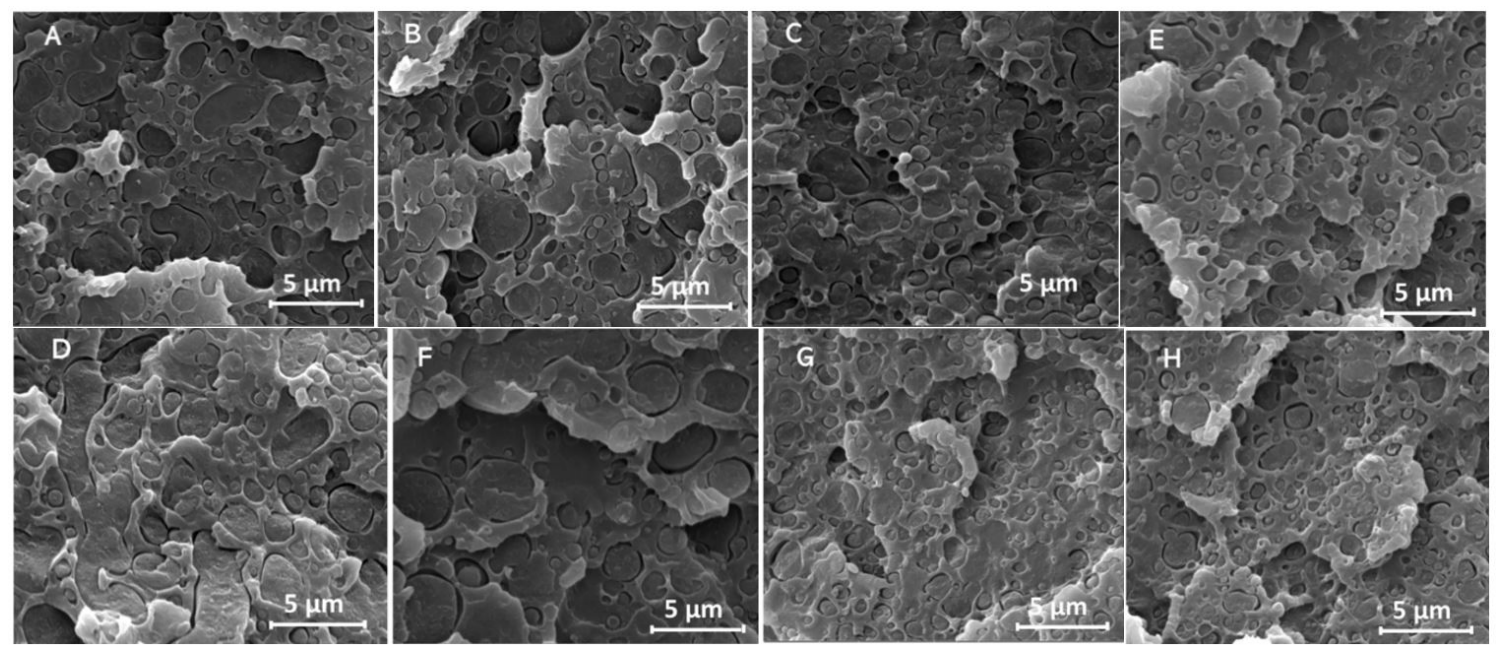

Figure 4. SEM micrographs of fractured surfaces of (A) PC/ABS (70/30), (B) PC/ABS/C3(70/25/5), (C) PC/ABS/C5(70/25/5), (D) PC/ABS/C6(70/25/5), (E) PC/ABS (85/15), (F) PC/ABS/C3(85/10/5), (G) PC/ABS/C5(85/10/5) and (F) PC/ABS/C6/85/10/5) with magnification of $15000 x$. 

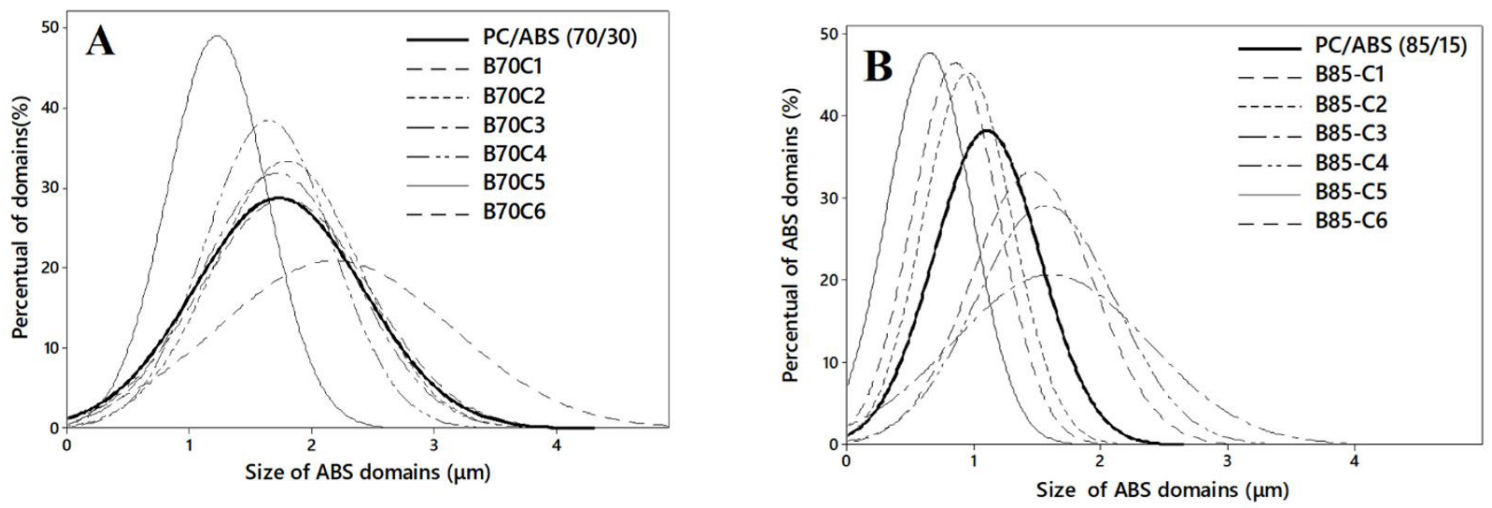

Figure 5. Size ABS domains distribution for PC/ABS with different blend ratio e ABS-g-MA composition (A) 70/30 and (A)85/15.

$\mathrm{C} 3$ and $\mathrm{C} 4$. A better dispersion and distribution of the $\mathrm{ABS}$ phase was observed for the PC/ABS blends that use $\mathrm{C} 5$.

Figure 5 shows the effect of compatibilizer addition in size distributions of $\mathrm{ABS}$ domains in blends PC/ABS (70/30) (Figure 5A) and PC/ABS (85/15) (Figure 5B), respectively. The distributions of the blend are represented in bold lines. Looking at both different blends compositions the thinner dispersion of PC/ABS (85/15) is confirmed quantitatively, agreeing with the qualitative analyses.

According to the Izod impact test, the compositions of ABS- $g$-MA ( 22 and $\mathrm{C} 5$ ) could be used for PC/ABS blends of both blend ratio. However, based on the sizes distribution is observed that the addition of $\mathrm{C} 5$ as compatibilizer agent is promoted the thinnest and narrowest distribution for both $\mathrm{PC} / \mathrm{ABS}$ blends compositions, indicating that it may be the best compatibilizer agent for that system.

\section{Conclusions}

Maleic anhydride was successfully melt grafted into ABS by a reactive extrusion process. The effectiveness of the ABS- $g$-MA as a compatibilizer agent has been confirmed for PC/ABS blends with different blend ratios (70/30 and 85/15). FTIR spectra of ABS-g-MA of all compositions showed a new characteristic band at $1780 \mathrm{~cm}^{-1}$ confirming the graft reaction of MA onto the $\mathrm{ABS}$ chain. Grafting degree analysis indicated a proportional increase with the MA and BPO content, MFI and rheological behavior suggested a reduction in the molecular weight of $\mathrm{ABS}$ due to chain scissions. For the PC/ABS blends, the Izod impact tests confirmed that ABS improved the PC impact strength and that ABS- $g$-MA compatibilizer agents $\mathrm{C} 2$ and $\mathrm{C} 5$ could be used for both blend ratios. The morphologies analyzed by SEM and qualitative analyzes of size $\mathrm{ABS}$ domains distribution suggests that ABS- $g$-MA composition $\mathrm{C} 5$ might be the best compatibilizer agent for PC/ABS blends.

\section{Acknowledgements}

The authors are grateful to Brazilian Funding institution FAPESP (Fundação de Amparo à Pesquisa do Estado de São Paulo - 2019/11130-9) and CNPq (Conselho Nacional de Desenvolvimento Científico e Tecnológico-310196/2018-3 and 405675/2018-6) for the financial support.

\section{References}

1. Mengual, A., Juárez, D., Balart, R., \& Ferrándiz, S. (2017). PE-g-MA, PP-g-MA and SEBS-g-MA compatibilizers used in material blends. Procedia Manufacturing, 13, 321-326. http:// dx.doi.org/10.1016/j.promfg.2017.09.083

2. Kim, I. C., Kwon, K. H., \& Kim, W. N. (2018). Gloss reduction and morphological properties of polycarbonate and poly(methyl methacrylate-acrylonitrile-butadiene-styrene) blends with SAN-co-GMA as a reactive compatibilizer. Journal of Applied Polymer Science, 135(27), 1-9. http://dx.doi.org/10.1002/ app. 46450 .

3. Ramesh, V., Biswal, M., Mohanty, S., \& Nayak, S. K. (2014). Compatibilization effect of EVA-g-MAH on mechanical, morphological and rheological properties of recycled PC/ ABS blend. Materials Express, 4(6), 499-507. http://dx.doi. org/10.1166/mex.2014.1198.

4. Utracki,A. L. (2002). Polymer Blends Handbook. Netherlands, Dordrecht: Springer.

5. Paul, D. R. (1978). Polymer Blends. New York: Academic Press. http://dx.doi.org/10.1016/B978-0-12-546802-2.50012-9.

6. Rzayev, Z. M. O. (2011). Graft copolymers of maleic anhydride and its isostructural analogues: High performance engineering materials. International Review of Chemical Engineering, 3, 153-215. http://dx.doi.org/10.15866/ireamt.v2i5.7001.

7. Zou, W., Huang, J., Zeng, W., \& Lu, X. (2020). Effect of ethylene-butylacrylate-glycidyl methacrylate on compatibility properties of poly (butylene terephthalate)/thermoplastic polyurethane blends. ES Energy\&Environment, 9, 67-73. http://dx.doi.org/10.30919/esee8c180.

8. Farzadfar, A., Khorasani, S. N., \& Khalili, S. (2014). Blends of recycled polycarbonate and acrylonitrile-butadiene-styrene: comparing the effect of reactive compatibilizers on mechanical and morphological properties. Polymer International, 63(1), 145-150. http://dx.doi.org/10.1002/pi.4493.

9. Zhao, B., Wang, Q., Hu, G., Wang, B., Li, Y., Song, J., Wang, Z., \& Li, Q. (2012). Effect of methyl methacrylate graft acrylonitrile-butadiene-styrene on morphology and properties of polycarbonate/acrylonitrile-butadiene-styrene blend. Journal of Macromolecular Science, Part B: Physics, 51(11), 22762283. http://dx.doi.org/10.1080/00222348.2012.672839.

10. Ryu, S. C., Kim, J. Y., \& Kim, W. N. (2018). Relationship between the interfacial tension and compatibility of polycarbonate and poly(acrylonitrile-butadiene-styrene) blends with reactive compatibilizers. Journal of Applied Polymer Science, 135(26), 1-10. http://dx.doi.org/10.1002/app.46418. 
11. Fu, Y., Song, H., Zhou, C., Zhang, H., \& Sun, S. (2013). Modification of the grafting character to prepare PA6/ABS$g$-MA blends with higher toughness and stiffness. Polymer Bulletin, 70(6), 1853-1862. http://dx.doi.org/10.1007/s00289012-0879-7.

12. Jang, S. P., \& Kim, D. (2000). Thermal, mechanical, and diffusional properties of nylon 6/ABS polymer blends: compatibilizer effect. Polymer Engineering and Science, 40(7), 1635-1642. http://dx.doi.org/10.1002/pen.11295.

13. dos Anjos, E. G. R., Backes, E. H., Marini, J., Pessan, L. A., Montagna, L. S., \& Passador, F. R. (2019). Effect of LLDPE$g$-MA on the rheological, thermal, mechanical properties and morphological characteristic of PA6/LLDPE blends. Journal of Polymer Research, 26(6), 1-10. http://dx.doi.org/10.1007/ s10965-019-1800-y.

14. Frund, Z. N. (2017). Reactive Extrusion. Weinheim, Germany: Wiley-VCH Verlag GmbH \& Co. KGaA.

15. Tjong, S. C., \& Meng, Y. Z. (2000). Effect of reative compatibilizers on the mechanical properties of polycarbotnate/ ABS blends. European Polymer Journal, 36, 123-129. http:// dx.doi.org/10.1016/S0014-3057(99)00044-0.

16. Montanheiro, T. L. A., Passador, F. R., Oliveira, M. P., Duran, N., \& Lemes, A. P. (2016). Preparation and characterization of maleic anhydride grafted poly (hydroxybutirate-COhydroxyvalerate)-PHBV-g-MA. Materials Research, 19(1), 229-235. http://dx.doi.org/10.1590/1980-5373-MR-2015-0496.

17. Das, V., Kumar, V., Singh, A., Gautam, S. S., \& Pandey, A. K. (2012). Compatibilization efficacy of LLDPE-g-MA on mechanical, thermal, morphological and water absorption properties of Nylon-6/LLDPE blends. Polymer-Plastics Technology and Engineering, 51(5), 446-454. http://dx.doi. org/10.1080/03602559.2011.639840.

18. Roeder, J., Oliveira, R. V. B., Gonçalves, M. C., Soldi, V., \& Pires, A. T. N. (2002). Polypropylene/polyamide- 6 blends: influence of compatibilizing agent on interface domains. Polymer Testing, 21(7), 815-821. http://dx.doi.org/10.1016/ S0142-9418(02)00016-8.

19. Ma, P., Jiang, L., Ye, T., Dong, W., \& Chen, M. (2014). Melt free-radical grafting of maleic anhydride onto biodegradable poly(lactic acid) by using styrene as a comonomer. Polymers, 6(5), 1528-1543. http://dx.doi.org/10.3390/polym6051528.

20. Qi, R., Chen, Z., \& Zhou, C. (2005). Solvothermal preparation of maleic anhydride grafted onto acrylonitrile-butadiene-styrene terpolymer (ABS). Polymer, 46(12), 4098-4104. http://dx.doi. org/10.1016/j.polymer.2005.02.116.

21. Qi, R., Qian, J., \& Zhou, C. (2003). Modification of acrylonitrilebutadiene-styrene terpolymer by grafting with maleic anhydride in the melt. I. Preparation and characterization. Journal of Applied Polymer Science, 90(5), 1249-1254. http://dx.doi. org/10.1002/app.12679.

22. Triantou, M. I., \& Tarantili, P. A. (2014). Studies on morphology and thermomechanical performance of ABS/PC/Organoclay hybrids. Polymer Composites, 35(7), 1395-1407. http://dx.doi. org/10.1002/pc.22792.

23. Li, H., Zhao, J., Liu, S., \& Yuan, Y. (2014). Polycarbonateacrylonitrile-butadiene-styrene blends with simultaneously improved compatibility and flame retardancy. RSC Advances, 4(20), 10395-10401. http://dx.doi.org/10.1039/c3ra45617j.

24. Brydson, J. (1999). Plastic Materials. Oxford, England: Butterworth-Heinemann.

25. Rao, B. M., Rao, P. R., \& Sreenivasulu, B. (2008). Grafting of maleic anhydride onto acrylonitrile-butadiene-styrene terpolymer: synthesis and characterization. Polymer-Plastics Technology and Engineering, 38(5), 967-977. http://dx.doi. org/10.1080/03602559909351625.
26. Balakrishnan, S., Neelakantan, N. R., \& Jaisankar, S. N. (1999). Effect of functionality levels and compatibility of polycarbonate blends with maleic anhydride grafted ABS. J Appl Journal of Applied Polymer Science, 74(8), 2102-2110. http://dx.doi. org/10.1002/(SICI)1097-4628(19991121)74:8<2102::AIDAPP27>3.0.CO;2-Y.

27. American Society for Testing and Materials - ASTM. (2013) ASTM D1238 - Standard Test Method for Melt Flow Rates of Thermoplastics by Extrusion Plastometer. West Conshohocken: ASTM. http://dx.doi.org/10.1520/D1238-13.

28. American Society for Testing and Materials-ASTM. (2018). ASTM D256 - Standard Test Methods for Determining the Izod Pendulum Impact Resistance of Plastics 1. West Conshohocken: ASTM. http://dx.doi.org/10.1520/D0256-10R18.

29. dos Santos, J. C. D., Panzera, T. H., Chistoforo, A. L., Vieira, K. D. O., Schiavon, M. A., \& Lahr, F. A. R. (2016). Thermoset polymer reinforced with silica micro and nanoparticles. Journal of Testing and Evaluation, 44(4), 1535-1541. http://dx.doi. org/10.1520/JTE20130331.

30. Abushowmi, T. H., AlZaher, Z. A., Almaskin, D. F., Qaw, M. S., Abualsaud, R., Akhtar, S., Al-Thobity, A. M., Al-Harbi, F. A., Gad, M. M., \& Baba, N. Z. (2020). Comparative effect of glass fiber and nano-filler Addition on denture repair strength. Journal of Prosthodontics, 29(3), 261-268. http://dx.doi. org/10.1111/jopr.13124. PMid:31696582.

31. Bokria, J. G., \& Schlick, S. (2002). Spatial effects in the photodegradation of poly(acrylonitrile-butadiene-styrene): A study by ATR-FTIR. Polymer, 43(11), 3239-3246. http:// dx.doi.org/10.1016/S0032-3861(02)00152-0.

32. Madhusudhan Rao, B., Raghunath Rao, P., \& Sreenivasulu, B. (1999). Grafting of maleic anhydride onto acrylonitrilebutadiene-styrene terpolymer: synthesis and characterization. Polymer-Plastics Technology and Engineering, 38(5), 967-977. http://dx.doi.org/10.1080/03602559909351625.

33. Braga, N. F., Zaggo, H. M., Montanheiro, T. L. A., \& Passador, F. R. (2019). Preparation of maleic anhydride grafted poly(trimethylene terephthalate) (PTT-g-MA) by reactive extrusion processing. Journal of Manufacturing and Materials Processing, 3(2), 37. http://dx.doi.org/10.3390/jmmp3020037.

34. Montanheiro, T. L. A., Menezes, B. R. C., Ribas, R. G., Montagna, L. S., Campos, T. M. B., Schatkoski, V. M., Righetti, V. A. N., Passador, F. R., \& Thim, G. P. (2019). Covalently $\gamma$-aminobutyric acid-functionalized carbon nanotubes: improved compatibility with PHBV matrix. SN Applied Sciences. 1, 1177. http://dx.doi.org/10.1007/s42452-019-1224-7

35. da Silva, T. F., Morgado, G. F. M., Montanheiro, T. L. A., Montagna, L. S., Albers, A. P. F., \& Passador, F. R. (2020). A simple mixing method for polyamide 12/attapulgite nanocomposites: structural and mechanical characterization. SN Applied Sciences, 2(3), 369. http://dx.doi.org/10.1007/ s42452-020-2153-1.

36. Lee, M. P., Hiltner, A., \& Baer, E. (1992). Fractography of injection molded polycarbonate acrylonitrile-butadiene-styrene terpolymer blends. Polymer Engineering and Science, 32(13), 909-919. http://dx.doi.org/10.1002/pen.760321311.

37. Greco, R., Astarita, M. F., Dong, L., \& Sorrentino, A. (1994). Polycarbonate/ABS blends: Processability, thermal properties, and mechanical and impact behavior. Advances in Polymer Technology, 13(4), 259-274. http://dx.doi.org/10.1002/ adv.1994.060130402.

Received: Oct. 19, 2020

Revised: Nov. 03, 2020

Accepted: Dec. 17, 2020 